\title{
CORRIGENDUM
}

\section{Circadian profiles in young people during the early stages of affective disorder}

\author{
SL Naismith, DF Hermens, TKC Ip, S Bolitho, E Scott, NL Rogers and IB Hickie
}

Translational Psychiatry (2013) 3, e217; doi:10.1038/tp.2012.127; published online 15 January 2013

Correction to: Translational Psychiatry (2012) 2, e123; doi:10.1038/tp.2012.47; published online 29 May 2012

Following the publication of this paper, it was raised to the authors' attention that Dr Scott's Conflict of Interest statement was incomplete. Dr Scott wishes to apologize for the omissions. The full Conflict of Interest statement appears below.

'IBH has led projects for health professionals and the community supported by governmental, community agency and drug industry partners (Wyeth, Eli Lilly, Servier, Pfizer, AstraZeneca) for the identification and management of depression and anxiety. He has served on advisory boards convened by the drug industry in relation to specific antidepressants, including nefazodone, duloxetine and desvenlafaxine, and has participated in a multicenter clinical trial of agomelatine effects on sleep architecture in depression. He has participated in Servier-sponsored educational programs related to circadian-based therapies. ES has participated in educational and professional training programs that were supported by several pharmaceutical companies, including Pfizer, AstraZeneca, Servier and Eli Lilly. She has also participated in clinical research funded by Pfizer (focused on experiences of care) and Servier (focused on sleep-wake cycle systems) and serves on an industry-advisory board supported by Pfizer.' 